\title{
Nanofundamentos da macroeconomia: Keynes e o institucionalismo na Teoria Geral
}

Huáscar Fialho Pessali ${ }^{1}$

Resumo: Há no capítulo 12 da Teoria Geral ("O estado da expectativa de longo prazo") alguns conceitos e conexões analíticas de base comportamental que apresentam forte identificação com elementos das abordagens que hoje conhecemos por institucionais. Quer-se neste ensaio enfatizar o quanto Keynes antecipou a agenda recente de tais abordagens institucionais por meio principalmente de suas considerações a respeito do comportamento dos indivíduos.

Palavras-chave: Keynes; keynesianismo; comportamento dos agentes; instituições; institucionalismo.

\section{Nano-foundations of macroeconomics: Keynes and the institutional elements in the General Theory}

\begin{abstract}
Chapter 12 of Keynes' General Theory has concepts and analytical links with strong identification with the ones used by the so-called institutional approaches. This essay highlights what seems to have been anticipated by Keynes on the research core of institutional economics, mainly based on his behavioural assumptions.
\end{abstract}

Key words: Keynes; Keynesian economics; economic behaviour; institutions; institutionalism.

JEL: B25; B31; D01; DO2

1 Departamento de Economia da UFPR. E-mail: pessali@ufpr.br. 


\section{Introdução}

A safra 1936-1937 foi excepcional na ciência econômica. Em 1936, John Commons publica na American Economic Review a segunda parte do seu "Institutional economics," um marco na área de direito e economia. Em 1937, Ronald Coase publica na Economica o seu "The nature of the firm," a pedra fundamental da nova economia institucional. No mesmo volume da Economica, Hayek publica o seu "Economics and knowledge," que reorienta a escola austríaca e marca profundamente o debate do cálculo socialista. Em 1936, John Maynard Keynes publica a sua obra mais influente, "The general theory of employment, interest and money," um divisor de águas na economia.

É interessante notar que cada uma dessas obras foi instrumental no desenvolvimento de áreas diferentes da economia. Commons é hoje conhecido por sua grande influência na área de direito e economia, principalmente nos Estados Unidos, e também como um dos mentores da escola institucional norte-americana. Coase recebeu o prêmio do Banco da Suécia (o "Nobel de Economia") em 1992 por seu trabalho com custos de transação e externalidades, e é hoje reconhecido como um dos pais da nova economia institucional. Hayek dividiu o "prêmio Nobel" em 1974 com Gunnar Myrdall, e a menção do Banco da Suécia foi feita à "sua análise profunda da interdependência dos fenômenos econômicos, sociais e institucionais." Keynes é hoje reconhecido como o pai da macroeconomia.

Mas aquela era uma época em que a ciência e a profissão ainda permitiam que pessoas cultas usassem suas capacidades para discussões mais abrangentes. Não seria de se espantar, portanto, que todas aquelas figuras tivessem algumas intersecções intelectuais. Se, porém, tanto os trabalhos de Commons quanto os de Coase e Hayek terminaram associados a alguma agremiação institucional dentro da economia, o mesmo não aconteceu com Keynes. Mas não teria Keynes também elaborado sua teoria com o que hoje reconhecemos ser pitadas institucionais?

Para tratar desta questão, vamos nos limitar a um capítulo da Teoria Geral (Keynes 1936). Obviamente o exercício poderia se estender a outras partes da obra de Keynes - o que exigiria uma discussão mais extensa do que a possível neste artigo. ${ }^{2} \mathrm{O}$ que se quer com isso é um foco mais estreito em detrimento de maior generalidade. Vale também dizer que a maior parte dos trabalhos que buscam identificar pontes entre a teoria Keynesiana e as teorias institucionalistas dão uma justa ênfase na noção de incerteza. A discussão feita aqui aceita plenamente tal cone-

2 Para exercícios dessa natureza vide por exemplo Vining (1939), Peterson (1977), Dillard (1980), Keller (1983), Lawson \& Lawson (1990), Chasse (1991), Minsky (1996), Atkinson \& Oleson (1998), Dequech (1999), Ferrari Filho \& Conceição (2001), Henry (2001) e Tymoigne (2003). 
xão e a mantém como pano de fundo, mas concentra-se em outros elementos. E, dentro das discussões possíveis a respeito de tais elementos, o que se busca enfatizar é a presença na Teoria Geral de temas importantes que mais tarde vieram a consagrar uma agenda de pesquisa institucionalista.

Há no capítulo 12 da Teoria Geral ("O estado da expectativa de longo prazo") alguns conceitos e conexões analíticas de natureza especialmente interessante para o exercício. (Claro, não se quer com isso defender que outras partes da obra de Keynes não possam ser exploradas com o mesmo intento.) Usando trechos daquele capítulo, vamos acrescentar entre colchetes conceitos hoje amplamente conhecidos e que fazem parte de uma agenda institucional na economia. Vamos então apresentá-los brevemente e discutir a propriedade de considerá-los na teoria Keynesiana.

\section{Formando expectativas de longo-prazo: informação incompleta e racionalidade limitada}

No capítulo 12 da Teoria Geral (TG), Keynes discute um dos fatores a determinar a renda esperada de um ativo - as expectativas de longoprazo. A renda esperada do ativo vai influenciar a eficiência marginal do capital, que por sua vez vai influenciar o volume de investimentos, condicionando o nível de emprego da economia.

De acordo com Keynes (TG:124):

Seria insensato, na formação de nossas expectativas, atribuir grande importância a tópicos que para nós são muito incertos. É, portanto, razoável que nos deixemos guiar, em grande parte, pelos fatos que merecem nossa confiança, mesmo se sua relevância for menos decisiva para os resultados esperados do que outros fatos a respeito dos quais o nosso conhecimento é vago e limitado [INFORMAÇÃO INCOMPLETA; RACIONALIDADE LIMITADA].

Considere também o seguinte trecho (TG:125):

O fato de maior importância é a extrema precariedade da base do conhecimento sobre a qual temos que fazer os nossos cálculos das rendas esperadas [INFORMAÇÃO INCOMPLETA]. O nosso conhecimento dos fatores que regularão a renda de um investimento alguns anos mais tarde é, em geral, muito limitado e, com freqüência, desprezível [RACIONALIDADE LIMITADA]. 
Tomar decisões a respeito de investimentos envolve avaliar o ambiente em sua complexidade. Keynes aponta para a existência corriqueira da incompletude da informação. Os indivíduos têm conhecimento apenas parcial de seu ambiente e é nesta condição que tomam suas decisões. Mas parece claro que não há qualquer consideração a respeito de informações completas. A formação de expectativas se dá com informações incompletas e, embora não se negue a possibilidade de mudanças de expectativas a partir de informações adicionais, a própria adição de informações pode se tornar um problema. Como disse Herbert Simon (1971), a riqueza de informações leva uma pobreza de atenção.

Avente-se por um momento a possibilidade de que seja possível ter informação completa - e.g., o indivíduo tem acesso a relatórios minuciosos sobre todas as empresas de capital aberto. Resta ainda ao indivíduo absorver tais informações, fazer sua decodifição e filtragem, combinar as partes que chegam segregadas, fazer e testar todas as conexões possíveis, organizar o "produto final" de forma a montar argumentos que sirvam à resolução de um problema (e.g., que investimento fazer), e antecipar os resultados possíveis de todos aqueles argumentos. Diante da dificuldade da tarefa - e considerando que o indivíduo não tem uma vida inteira para tomar uma decisão - vê-se que o indivíduo tem seus limites. Disponibilizar ainda mais informações ao indivíduo não vai necessariamente ajudá-lo a tomar uma decisão ótima ou melhor nos próximos cinco minutos (ou antes que as informações disponíveis se tornem obsoletas).

A tomada de decisões sob incerteza é sem dúvida um tópico explorado com densidade a partir da obra de Keynes. Considerações mais sistemáticas aos problemas do indivíduo, porém, não receberam de imediato a mesma atenção. A ênfase dada aos seus aspectos macroeconômicos talvez tenha requerido muito dos esforços dos estudiosos. Os estudos a respeito de microfundamentos da macroeconomia (mais ou menos próximos do mainstream) foi talvez o que mais interesse despertou dentro do keynesianismo (vide Possas 1993). De toda forma, isso mostra que a partir da obra de Keynes há elementos do que hoje se conhece por racionalidade limitada.

Independente da tentativa de conexão entre o micro e o macro, a noção de racionalidade limitada foi usada por Simon (1957) e começou a ganhar espaço em áreas como teorias da complexidade, teorias da organização, organização econômica e organização industrial, e a incitar uma aproximação maior entre a psicologia e a ciência econômica. Segundo Simon (1987:266), o conceito de racionalidade limitada expressa "a escolha racional que leva em conta os limites cognitivos do tomador de decisão - limites tanto de conhecimento quanto de capacidade de processamento." A idéia de limites da racionalidade humana, porém, é 
identificável na literatura econômica de forma tímida desde pelo menos 1880, considerando-se uma terminologia que se assemelhe à usada hoje em dia. ${ }^{3}$ Embora a idéia só tenha se propagado com mais força a partir da contribuição de Simon, ela estava presente nas discussões de institucionalistas como Veblen, Commons e Clark (Pagano 2000). E estava também no capítulo 12 da Teoria Geral. O argumento mais polêmico de Simon - a racionalidade limitada implicando num comportamento que busca satisfazer certos objetivos mínimos (satisficing) em contraposição à busca da otimização - parece fazer parte da visão de Keynes sobre o agente econômico na Teoria Geral. Acompanhe a passagem que segue (TG:134): "a nossa inteligência faz o melhor possível para escolher o melhor que pode haver entre as diversas alternativas, calculando sempre que se pode, mas retraindo-se, muitas vezes, diante do capricho, do sentimento ou do azar [SATISFICING]."

Vale dizer que o programa de pesquisa de Simon sobre racionalidade limitada o levou ao Prêmio Nobel de economia em 1978, além de ter sido absorvido como um dos pilares de boa parte da Nova Economia Institucional, de ter a simpatia do institucionalismo original e de ser a base de boa parte das teorias que se denominam evolucionárias. Keynes parecia estar à frente de seu tempo.

\section{Formando expectativas de longo-prazo a partir de hábitos}

A importância da formação de expectativas na tomada de decisões dos agentes não pode ser de forma alguma menosprezada na Teoria Geral. Diante da incerteza sobre os acontecimentos futuros e de nossa racionalidade limitada, temos que tomar decisões hoje sobre investimentos que se desdobrarão no futuro. Que tipo de orientação seguimos nesses momentos?

Keynes sugere que nos baseamos em certos hábitos - o principal deles sendo o de projetar o que conhecemos no presente para o futuro (TG: 124):

Por essa razão, os fatos atuais desempenham um papel que, em certo sentido, podemos julgar desproporcional na formação de nossas expectativas a longo prazo, sendo que o nosso método habitual consiste em considerar a situação atual e depois projetá-la no futuro [HÁBITOS], modificando-a apenas à medida que tenhamos razões mais ou menos definidas para esperarmos uma mudança.

3 Vide Klaes \& Sent (2005). O próprio Simon (1991) sugere ter sido inspirado pela obra de John R. Commons para desenvolver sua noção de racionalidade limitada. 
A ação baseada no comportamento habitual é a base da teoria comportamental de Veblen. Na sua crítica ao "calculador relâmpago" da teoria neoclássica, Veblen (1899) observou que nossas decisões são mais baseadas em hábitos formados ao longo de nossa vida do que em reavaliações constantes de nossas práticas em função de critérios de otimização. Observe-se também que há vários fatores a influenciar a formação de nossos hábitos, levando a comportamentos coletivos diferentes. Há diferentes racionalidades em diferentes culturas (que, aliás, podem ser definidas como um conjunto de hábitos coletivos). Veja por exemlo a seguinte passagem da TG (p. 131): "Diz-se ser raro um americano investir, como o fazem ainda muitos ingleses, 'para obter uma renda,' e que somente na expectativa de um ganho de capital está disposto a adquirir um título."

Esta passagem pode também ser relacionada à visão de modelos mentais construída por Denzau \& North (1994). Estes autores argumentam que somos indivíduos com limitações cognitivas para entender o mundo à nossa volta e por isso construímos (e precisamos manter) padrões de interpretação e avaliação do ambiente complexo e incerto. Veja então que o modelo mental corrente do agente keynesiano é o que orienta suas ações presentes com conseqüências futuras.

O comportamento humano considerado na Teoria Geral é não apenas derivado do hábito, mas também sujeito a distorções intrínsecas. Veja por exemplo a seguinte passagem (TG: 128):

As flutuações de curto prazo dos lucros nos investimentos existentes, embora sejam manifestamente efêmeras e desprovidas de significância, tendem a exercer sobre o mercado uma influência excessiva e mesmo absurda [VIÉS COMPORTAMENTAL]. Diz-se, por exemplo, que as ações das empresas norte-americanas que fabricam gelo podem ser vendidas a um preço mais elevado no verão, quando os seus lucros são, sazonalmente, elevados, do que no inverno, quando ninguém quer gelo.

Esse tipo de problema orienta a agenda de pesquisa de mais um ganhador do "prêmio Nobel" de economia, Daniel Kahneman (Kahneman \& Tversky 1973, 1979; Tversky \& Kahneman 1974). O problema do viés não é corrigido pelo mercado - justamente porque o mercado é formado por aqueles agentes que criam ou seguem uma convenção viesada. Muito embora seja possível racionalizar um ou outro tipo de viés e apresentá-lo ao agente no intuito de "corrigi-lo," toda informação repassada ao agente na forma de qualquer linguagem precisa ser decodificada e interpretada de acordo com hábitos e modelos mentais diferentes. Decisões de produção agrícola são talvez o exemplo mais persistente de como um certo hábito de comportamento (com viés 
expectacional) influencia as expectativas de longo-prazo dos agentes e assim suas decisões correntes.

\section{Deliberação instintiva}

A princípio, um hábito pode surgir de deliberações maximizadoras. A sua manutenção, porém, dificilmente se explica da mesma forma. ${ }^{4}$ Mas além do hábito e de possíveis deliberações maximizadoras, há de se considerar também o comportamento instintivo. É o que fazem Keynes no capítulo 12 da TG e boa parte dos autores institucionalistas (Veblen 1914; Hodgson 2004).

Embora hábitos e costumes coletivos possam ser mais importantes nos processos decisórios, há ainda certas pré-disposições comportamentais difíceis de racionalizar que carregamos conosco e que influenciam nossas decisões. Há certos momentos de crise, por exemplo, em que o medo explica certos cursos de ação. Em outros momentos de crise, uma propensão à imitação é deflagrada e se sobrepõe a processos custosos de coleta e processamento ótimo de informações. Há ainda momentos em que o instinto de sobrevivência leva o indivíduo a uma certa "bravura" que vai além de qualquer racionalização justificável.

Observe como Keynes explica o comportamento empresarial na passagem abaixo (TG: 125):

Em outros tempos, quando as empresas pertenciam, quase todas, aos que as tinham fundado ou aos seus amigos e sócios, o investimento dependia da existência de um número suficiente de indivíduos de temperamento entusiástico e de impulsos construtivos [INSTINTOS] que empreendessem negócios como uma maneira de viver, sem realmente tomar como base os cálculos precisos de lucros prováveis.

E ainda mais explicitamente neste trecho (idem):

Se a natureza humana não sentisse a tentação de arriscar a sorte, nem de sentir a satisfação (excluindo-se o lucro) de construir uma fábrica, uma estrada de ferro, de explorar uma mina ou uma fazenda [Veblen: IDLE CURIOSITY; INSTINCT OF WORKMANSHIP], provavelmente não haveria muitos investimentos como mero resultado de cálculos frios.

4 A não ser por via de otimização de meta-preferências, o que pode também se tornar um metahábito e exigir a otimização de meta-meta-preferências, etc. (vide Stigler \& Becker 1977 e Sen 1977). 
Fica claro que não é qualquer um de nós, por exemplo através da socialização (e.g., educação formal ou informal), que pode ser levado a executar certas tarefas profissionais. No caso dos agentes envolvidos com os mercados financeiros, por exemplo, Keynes observa claras diferenças para com o cidadão comum (TG: 130):

\begin{abstract}
A natureza humana exige sucessos imediatos, há um deleite especial em ganhar dinheiro rapidamente e os lucros remotos são descontados pelo homem médio a taxas muito elevadas [HÁBITOS; INSTINTOS]. O jogo dos investidores profissionais é intoleravelmente fastidioso e demasiado exigente para quem não tenha absolutamente o instinto de jogador [INSTINTOS].
\end{abstract}

E fica ainda mais evidente a importância atribuída por Keynes ao comportamento instintivo quando retornamos ao trecho sobre animal spirits após termos visto um pouco da literatura institucional. Para facilitar o exercício, aí vai a passagem (TG: 133): "Provavelmente, a maior parte das nossas decisões de fazer algo positivo (...) deva ser considerada como manifestação do nosso entusiasmo (animal spirits) - como um instinto espontâneo de agir, em vez de não fazer nada (...)" [INSTINTOS].

Vale lembrar que esta percepção em muito se assemelha ao que Veblen (1914) chamou de idle curiosity, um ímpeto a agir e resolver problemas que transcende qualquer justificativa utilitarista ou hedonística em qualquer formato.

Keynes apresenta o polimento final do argumento como segue (TG: 134):

As decisões humanas que envolvem o futuro, sejam elas pessoais, políticas ou econômicas, não podem depender da estrita expectativa matemática, uma vez que as bases para realizar semelhantes cálculos não existem e que o nosso impulso inato para a atividade é que faz girar as engrenagens [RACIONALIDADE LIMITADA; INSTINTOS].

Tanto à época de Veblen quanto agora, a agenda institucionalista insiste na tríade instintos, hábitos e razão para explicar o comportamento humano relevante às suas decisões econômicas (Twomey 1998; Vanberg 2002; Hodgson 2004). Não parece ser diferente com Keynes na TG.

\title{
4. O comportamento racional diante de tantas dificuldades: convenções
}

O indivíduo, então, usa todos os seus diferentes recursos neurofisiológicos no processo decisório na tentativa de lidar com a in- 
certeza e a complexidade. Todos estes recursos o levam a adotar padrões de comportamento estável, resistentes a certas variações no ambiente. Os de mais fácil identificação pelo leitor são sem dúvida os de cunho pessoal. Mas analiticamente se pode também considerar os hábitos de essência coletiva, originados na interação entre indivíduos, na observação e absorção de práticas socializadas. Tais práticas são as chamadas convenções.

Há uma vasta literatura associada ao estudo das convenções e não seria fácil separar todos os fios do emaranhado de variantes. $\mathrm{O}$ interesse maior dos economistas por este tema parece estar fortemente associado ao potencial de formalização permitido pelo desenvolvimento da teoria dos jogos, o que vem laureando certos autores com um Nobel (e.g., Nash, Harsanyi, Aumann e Schelling). Como se argumenta neste trabalho, isso não desmerece o tratamento dado ao tema por Keynes na TG. Pelo contrário, mostra mais uma vez o quanto ele se antecipou de modo ímpar à preocupação de seus pares. Se não, vejamos.

Keynes explica que indivíduos racionalmente limitados tendem a confiar na continuidade do estado presente dos mercados e a ignorar sinais discretos de mudança - muito embora as maiores oportunidades de lucro estejam em tentar antecipar tais possíveis oscilações. Essa nossa tendência em acomodar um comportamento socialmente habitual é explicada da seguinte forma na TG (126):

Na prática, concordamos, geralmente, em recorrer a um método que é, na verdade, uma convenção [CONVENÇÕES]. A essência desta convenção (...) reside em se supor que a situação existente dos negócios continuará por tempo indefinido, a não ser que tenhamos razões concretas para esperar uma mudança.

Logo em seguida, Keynes deixa claro que tal tipo de comportamento se origina da interação de indivíduos que detêm informação incompleta e que só podem processá-la de maneira limitada. O resultado, como fica claro, é a confluência de julgamentos parciais (TG: 128): "Uma avaliação convencional, fruto da psicologia de massa de grande número de indivíduos ignorantes [CONVENÇÕES, RACIONALIADE LIMITADA], está sujeita (...)".

Essa confluência rumo a uma convenção tem um substrato social importante, desafiando a análise racionalista tradicional. Veja na passagem seguinte o que Keynes foi capaz de perceber a partir de sua discussão sobre convenções (TG: 130): “A sabedoria universal indica ser melhor para a reputação fracassar junto com o mercado (conventionally) do que vencer contra ele (unconventionally) [CONVENÇÕES; COMPORTAMENTO MIMÉTICO].” 
Keynes nota que os indivíduos na maior parte do tempo não querem ser considerados outcasts. Eles preferem antes perder tendo seguido o comportamento aceito e praticado pelos demais a ganhar tendo que contrariálos. A análise tradicional não dá conta de explicar tal comportamento a não ser, claro, ao dizer que o comportamento mimético otimiza a utilidade do agente de alguma maneira. A análise institucional, por outro lado, esforça-se por entender e considerar as convenções como uma faceta diferente das decisões econômicas. Vê-se que tal esforço era também o de Keynes na TG.

\section{Problemas de agência na TG}

Uma outra agenda de pesquisa que ganhou espaço na ciência econômica recente foi a dos problemas do tipo agente-principal (ou de agência). Embora muitos questionem metodologicamente seu caráter institucional, a teoria da agência tem tido grande impacto em estudos sobre instituições. ${ }^{5}$

Berle \& Means (1932) é em geral reconhecido como o trabalho pioneiro na análise sistemática dos problemas oriundos da separação entre propriedade e gerência da firma, um tópico trabalhado por vários autores hoje vistos como institucionalistas (vide por exemplo Williamson 1964). A idéia, porém, acabou sendo refinada e generalizada como um problema característico de situações em que há assimetria de informações entre agentes econômicos - o problema existente entre agentes e principais.

Um dos principais formuladores desta teoria da agência foi o economista (e Nobelista de 2001) Michael Spence. Em sua Nobel Lecture, Spence disse ter respondido com uma negativa à pergunta de um jornalista sobre ser possível ganhar um Nobel teorizando a respeito de mercados em que algumas pessoas têm mais informações que outras. Se Spence errou (e deve ter ficado feliz por isso), então façamos uma pequena justiça a Keynes na TG.

Primeiramente, atento às implicações da separação entre propriedade e controle estudadas por Berle e Means, Keynes aplica a análise aos mercados de investimentos. Acompanhe a seguinte passagem (TG: 1256):

Com a separação entre a propriedade e a gestão que prevalece atualmente e com o desenvolvimento de mercados financeiros 
organizados, surgiu um novo fator de grande importância que, às vezes, facilita o investimento, mas que, às vezes, contribui sobremaneira para agravar a instabilidade do sistema [SEPARAÇÃO ENTRE PROPRIEDADE E CONTROLE]. (...) Destarte, certas categorias de investimento são reguladas pela expectativa média dos que negociam na bolsa de valores, tal como se manifesta no preço das ações, em vez de expectativas genuínas do empresário profissional [PROBLEMAS DE AGÊNCIA].

A separação entre o empresário profissional (o principal) e os investidores profissionais (os agentes) tem conseqüências sobre como são reguladas certas categorias de investimento. O empresário delega certas decisões de investimento a agentes, e estes se orientam não necessariamente pelos interesses, objetivos e preocupações de seu principal. Vai caber ao empresário incorrer em custos para monitorar seus agentes e criar incentivos para que se orientem pelos interesses do principal mecanismos que vêm se tornando cada vez mais complexos, custosos e, aparentemente, problemáticos em vários aspectos.

Mas este é apenas um lado das implicações, o da firma. Keynes, por outro lado, deteve-se nas implicações do problema de agência no agregado (TG: 128):

\begin{abstract}
Talvez se tenha suposto que a concorrência entre os profissionais competentes, dotados de julgamento mais seguro e de conhecimentos mais amplos do que o investidor privado médio, corrigiria os devaneios do indivíduo ignorante e à mercê de sua própria iniciativa. Sucede, porém, que (...) não se preocupam com o que realmente significa um valor de investimento para o indivíduo que o comprou "para guardar," mas com o valor que lhe atribuirá o mercado dentro de três meses ou um ano sob a influência da psicologia de massas [ASSIMETRIA DE INFORMAÇÃO; PROBLEMAS DE AGÊNCIA].
\end{abstract}

Na passagem que segue, vê-se de outra maneira como Keynes considera o problema de assimetria de informações que caracteriza o problema de agência. Além disso, pode-se ver que ele lida também com um outro tópico central a análises institucionais que se denominam evolucionárias: o problema do conhecimento tácito (TG: 128):

Como resultado do aumento gradual da proporção que representam no investimento agregado de capital da comunidade as ações possuídas por pessoas que não dirigem nem têm conhecimento especial das circunstâncias [ASSIMETRIA DE INFORMAÇÕES], reais ou esperadas, dos negócios em questão, há uma séria redução do elemento de real conhecimento a avalização desses investimentos feita pelos que os possuem ou pelos que tencionam adquiri-los [CONHECIMENTO TÁCITO]. 
O problema de agência detectado por Keynes tem sérias implicações sobre a dinâmica do investimento. Ela passa a incorporar as potenciais discrepâncias entre principal (o empresário produtivo) e agente (o investidor profissional). A conseqüência mais nítida na ótica do agregado é o tão comentado descolamento entre o mundo das finanças e o mundo da produção.

\section{Desenho institucional na TG}

Por fim, lembremos do que tem sido a segunda fase do chamado consenso de Washington. Após a primeira fase em que se destacava a estabilidade macroeconômica, a agenda dos organismos internacionais derivados de Bretton Woods se volta para as reformas institucionais. Muito do que se discute nessa área engloba o papel das instituições no desempenho das economias nacionais. E talvez a figura de maior destaque no campo teórico seja o economista (e Nobelista de 1993) Douglass North.

North (1993) sugere que as instituições podem ser comparadas, pelo menos parcialente, às regras de um jogo. Ele exemplifica a idéia comentando a existência de estruturas institucionais que recompensam (ou que deixam de coibir) a pirataria: a implicação mais imediata é que os "jogadores" ou as organizações voltarão seus esforços para aprender a ser bons piratas. Por outro lado, North considera a existência de uma outra estrutura institucional que garanta direitos de propriedade sobre o produto da atividade econômica: a implicação mais imediata é ver "jogadores" voltando seus esforços para o aumento da produtividade, que pode levar ao crescimento econômico. ${ }^{6}$

Bom, a participação de Keynes nas negociações de Bretton Woods já mostrava sua preocupação com o desenho das instituições que viriam a influenciar a dinâmica da economia global. Essa preocupação já fazia parte do aparato analítico desenvolvido na TG.

Comecemos observando como Keynes relaciona o comportamento dos indivíduos - no caso, os profissionais de investimento - à existência de uma instituição - o mercado financeiro (TG:128):

Ademais, essa conduta não é o resultado de uma propensão mal direcionada, mas a conseqüência inevitável de um mercado financeiro

6 Não se quer dizer que um país ou região voltado à pirataria - tanto nas versões marítimas épicas de França, Holanda e Inglaterra entre os séculos XV e XVII, como nas versões contemporâneas do Japão no pós-Segunda Guerra ou China desde a década de 1990 - não seja capaz de atingir o crescimento econômico. Ele porém vai depender de outrem que se dedique a produzir riquezas e não consiga protegê-las. 
organizado segundo as normas descritas [INSTITUIÇÕES; INCENTIVOS; FORMAÇÃO DE PREFERÊNCIAS; REGRAS DO JOGO].

Ou seja, o comportamento dos profissionais do investimento é influenciado pelos moldes da instituição onde ganham o pão. Mesmo o problema de auto-seleção (indivíduos de "propensão mal direcionada" preferem trabalhar como profissionais do investimento) pode ser influenciado pela natureza da instituição. Se os mercados financeiros têm normas rígidas de punição (e as implementam) ao comportamento "mal direcionado" ou se têm uma constituição que recompensa "propensões bem direcionadas," então há condições melhores para o casamento de interesses entre empresários produtivos e profissionais do investimento.

Tanto a instituição influencia os agentes com ela envolvidos que convenções ou instituições se criam ali dentro, como se tivessem vida própria. A literatura de sociologia das organizações, por exemplo, reconhece isso dentro de empresas sob o conceito de cultura organizacional. Numa instituição como o mercado financeiro, que envolve uma diversidade de organizações, o resultado pode ser o que Keynes descreveu da seguinte forma (TG:129):

Essa luta de esperteza para prever com alguns meses de antecedência as bases da avaliação convencional [entre os profissionais é uma partida que] pode ser jogada entre estes mesmos [INSTITUIÇÕES DENTRO DE INSTITUIÇÕES; INEFICIÊNCIA INSTITUCIONAL].

Keynes deduziu de sua experiência que, a partir de tais interações, as mudanças feitas no desenho institucional dos mercados financeiros teriam implicações sobre seu funcionamento e, portanto, seu desempenho (TG: 131): "À medida que progride a organização dos mercados de investimento [MUDANÇA INSTITUCIONAL; INEFICIÊNCIA INSTITUCIONAL], o risco de um predomínio da especulação, entretanto, aumenta."

Mas, como análises institucionais comparativas têm crescentemente defendido, não basta falar dos problemas de uma instituição como se houvesse a possibilidade de termos uma instituição sem problemas. É sempre útil tecer comparações com outras instituições. Keynes faz esse exercício ao comparar o mercado financeiro inglês ao norte-americano (TG:132):

O fato de que os pecados da Bolsa de Valores de Londres tenham sido menores do que os de Wall Street talvez não se deva tanto a diferenças nos temperamentos nacionais como à circunstância de que, para o 
inglês mediano, Throgmorton Street é inacessível e muito dispendiosa comparada com Wall Street para o mesmo tipo de norte-americano [DESENHO INSTITUCIONAL; ANÁLISE COMPARATIVA DE CUSTOS DE TRANSAÇÃO].

Keynes aqui evidencia tanto o papel das instituições formais quanto das informais. Há, porém, duas mensagens aparentemente conflitantes nesta passagem. Keynes deixa de lado as diferenças de "temperamento" entre ingleses e norte-americanos para justificar as diferenças de desempenho e os diferentes problemas de seus respectivos mercados financeiros. Ele concentra sua explicação nos diferentes desenhos institucionais e conseqüentes custos de entrada e permanência nos mercados financeiros dos dois países. Um problema aparente com este argumento é que os temperamentos podem influenciar na montagem de instituições diferentes. O temperamento inglês pode incitar maior precaução que o norte-americano, o que se reflete no desenho do mercado financeiro que os ingleses querem ter. $\mathrm{O}$ animal spirit (que tem relação com o nosso temperamento) não precisa ser homogêneo, nem as convenções do jogo entre os profissionais do investimento.

Se podemos dizer que o argumento de Keynes pode receber um retoque neste ponto, podemos por outro lado dizer que ele se antecipou em fazer uma análise comparativa de custos de transação. Este tipo de preocupação ganhou sua forma moderna principalmente com o trabalho de Oliver Williamson (1975), um dos expoentes da Nova Economia Institucional. Os custos de transação são aqueles incorridos na busca de informações e na preparação de uma transação econômica, bem como os que estão implicados em especificar o que é a transação e garantir sua execução. Keynes, na passagem acima, percebe que o mercado financeiro inglês tem custos de transação mais elevados nas movimentações de investimento do que os custos incorridos pelos norte-americanos em Wall Street. Keynes parece entender, por exemplo, que o desenho institucional de Wall Street segue o que a economia dos custos de transação identificaria como minimização de custos de transação para mostrar-se mais acessível e eficiente. Neste caso específico, porém, Keynes não parece crer nessa estratégia como a melhor opção para garantir estabilidade de longo prazo.

\section{Comentários finais}

Não devemos concluir daí que tudo depende de ondas de psicologia irracional. (TG:134)

Quando se tem racionalidade limitada e informação incompleta e assimetricamente distribuída não é irracional seguir convenções, assim 
como não é irracional construir hábitos de comportamento para lidar com a incerteza do ambiente e a incerteza relativa ao comportamento alheio. E nada disso significa que abandonamos a razão como recurso de seleção, processamento e concatenação de informações para a tomada de decisões econômicas.

Diante disso, pode-se perceber que os indivíduos apresentados por Keynes no capítulo 12 da TG têm muito do que as abordagens institucionais modernas consideram elementos centrais de análise. Sob o microscópio, os nanofundamentos da macroeconomia de Keynes na TG têm fortes afinidades com a economia institucional praticada em sua época e antecipam muitas das preocupações da economia institucional contemporânea.

Mesmo diante de tais afinidades com o institucionalismo do início do século XX, as contingências históricas e a dinâmica interna da ciência econômica acabaram por afastar Keynes daquela bandeira. O esforço de resgatar tais ligações parece válido, no mínimo, para dar créditos intelectuais a quem merece numa época em que a economia institucional discute a relevância dos direitos de propriedade para o bom funcionamento das instituições. Mas há também os que acreditam em aprender com o passado. E, se o assunto em voga para deguste intelectual é instituições, não se pode esquecer que a safra 1936-1937 foi excepcional.

\section{Referências}

ATKINSON, Glen \& OLESON Jr., Theodore (1998). “Commons and Keynes: their assault on laissez faire". Journal of Economic Issues 32(4):1019-30.

BERLE, Adolf \& MEANS, Gardiner (1932). The modern corporation and private property. Nova Iorque: Commerce Clearing House.

CHASSE, John (1991). “John R. Commons and John Maynard Keynes: two philosophies of action.” Journal of Economic Issues 25(2):441-48.

COASE, Ronald H. (1937). "The nature of the firm." Economica 4:386-405.

COMMONS, John R. (1936). "Institutional economics." American Economic Review 26(1):237-49.

DENZAU, Arthur \& NORTH, Douglass (1994). "Shared mental models: ideologies and institutions." Kyklos 1(3):3-31.

DEQUECH, David (1999). "Expectations and confidence under uncertainty." Journal of Post Keynesian Economics 21(3):415-30.

DILLARD, Dudley (1980). “A monetary theory of production: Keynes and the institutionalists." Journal of Economic Issues 14(2):255-73. 
FERRARI FILHO, Fernando \& CONCEIÇÃO, Octavio A. (2001). "A noção de incerteza nos pós-keynesianos e institucionalistas: uma conciliação possível?" Nova Economia 11(1):99-122.

HAYEK, Friederich (1937). “Economics and knowledge." Economica 4:3354 .

HENRY, John (2001). "Keynes' economic program, social institutions, ideology, and property rights." Journal of Economic Issues 35(3):633-55.

HODGSON, Geoffrey (2004). "Reclaiming habit for institutional economics." Journal of Economic Psychology 25:651-60.

JENSEN, M. \& MECKLING, W. (1976). "Theory of the firm: managerial behavior, agency costs and ownership structure." The Journal of Financial Economics 3:305-60.

KAHNEMAN, Daniel \& TVERSKY, Amos (1973). "On the psychology of prediction." Psychological Review 80:237-51.

KAHNEMAN, Daniel \& TVERSKY, Amos (1979). "Prospect theory: an analysis of decisions under risk." Econometrica 47:313-27.

KELLER, Robert (1983). "Keynesian and institutional economics: compatibility and complementarity?” Journal of Economic Issues 17(4):108795 .

KEYNES, John M (1993) [1936]. The general theory of employment, interest and money. In The Collected Writings of John Maynard Keynes, v. VII. Londres: Macmillan.

KEYNES, John M. (1982). A teoria geral do emprego, do juro e da moeda. São Paulo: Atlas.

KLAES, M. \& SENT, E.-M. (2005). “A conceptual history of the emergence of bounded rationality." History of Political Economy 37(1):27-59.

LAWSON, Catherine \& LAWSON, Larry (1990). "Financial system restructuring: lessons from Veblen, Keynes, and Kalecki." Journal of Economic Issues 24 (1): 115-31.

MINSKY, Hyman (1996). "Uncertainty and the institutional structure of capitalist economies." Journal of Economic Issues 30(2):357-68.

NORTH, Douglass (1993). "Institutions and economic performance.” In MÄKI, U. \& GUSTAFSSON, B. \& KNUDSEN, C. (orgs.) Rationality, institutions and economic methodology. Londres: Routledge.

PAGANO, Ugo (2000). "Bounded rationality, institutionalism and the diversity of economic institutions." In LOUÇÃ, F. \& PERLMAN, M. (eds). Is economics an evolutionary science? Cleltman (UK) \& Nothampton (MA): Edward Elgar.

PESSALI, Huáscar \& FERNÁNDEZ, Ramón (2006). "Inovação e teorias da firma.” In PELAEZ, V. \& SZMRECSÁNYI, T. (orgs). Economia da inovação tecnológica. Campinas: Hucitec.

PETERSON, Wallace (1977). "Institutionalism, Keynes, and the real world." Journal of Economic Issues 11(2):201-21. 
POSSAS, Mário (1993). "Racionalidade e regularidades; rumo a uma integração micro-macrodinâmica.” Economia e Sociedade 1(2):59-80.

SEN, Amartya (1977). "Rational fools: a critique of the behavioral foundations of economic theory." Philosophy and Public Affairs 6(4):317-44.

SIMON, Herbert (1957). Models of man. Nova Iorque: Wiley.

SIMON, Herbert (1971). "Designing organizations for an information-rich world.” In GREENBERGER, M. (ed.). Computers, communications, and the public interest. Baltimore \& Londres: The Johns Hopkins Press.

SIMON, Herbert (1987). "Bounded rationality.” In EATWELL, J. \& MILGATE, M. \& NEWMAN, P. (eds). The New Palgrave Dictionary of Economics. Londres: Macmillan.

SIMON, Herbert (1991). Models of my life. Nova Iorque: Basic Books.

STIGLER, G. \& BECKER, G. (1977). "De gustibus non est disputandum." American Economic Review 67(2):76-90.

TVERSKY, Amos \& KAHNEMAN, Daniel (1974). "Judgment under uncertainty: heuristics and biases." Science 185(4157):1124-31.

TWOMEY, P. (1998). "Reviving Veblenian economic psychology." Cambridge Journal of Economics 22(4):433-48.

TYMOIGNE, Éric (2003). "Keynes and Commons on money." Journal of Economic Issues 37(3):527-45.

VANBERG, V. (2002). "Rational choice versus program-based behavior: alternative theoretical approaches and their relevance for the study of institutions." Rationality and Society 14(1):7-53.

VEBLEN, Thorstein (1899). The theory of the leisure class: an economic study of institutions. Nova Iorque: Macmillan.

VEBLEN, Thorstein (1914). The instinct of workmanship and the state of the industrial arts. Nova Iorque: Macmillan.

VINING, Rutledge (1939). "Suggestions of Keynes in the writings of Veblen." The Journal of Political Economy 47(5):692-704.

WILLIAMSON, Oliver (1964). The economics of discretionary behavior: managerial objectives in a theory of the firm. Englewood Cliffs, NJ: PrenticeHall.

WILLIAMSON, Oliver (1975). Markets and hierarchies: analysis and antitrust implications. Nova Iorque: The Free Press.

Artigo recebido em 01/07/2006. Aceite em 04/08/2006. 